\title{
Pharmacists' Knowledge, Attitudes and Beliefs Regarding Intervention for Prescription Medicines Abuse
}

\author{
Sadia Shakeel ${ }^{*}$, Wajiha Iffat ${ }^{1}$, Sadaf Ibrahim ${ }^{2}$, Shehla Imam ${ }^{3}$ \\ ${ }^{1}$ Dow University of Health Sciences, Karachi, Pakistan \\ ${ }^{2}$ Baqai Medical University, Karachi, Pakistan \\ ${ }^{3}$ Faculty of Pharmacy, University of Karachi, Karachi, Pakistan \\ Email: *sadia.shakeel@duhs.edu.pk
}

Received 23 October 2015; accepted 6 November 2015; published 11 November 2015

Copyright (C) 2015 by authors and OALib.

This work is licensed under the Creative Commons Attribution International License (CC BY).

http://creativecommons.org/licenses/by/4.0/

(c) (i) Open Access

\section{Abstract}

Background: Abuse of medicines is becoming a serious problem in many parts of the world, with negative consequences ranging from addiction, psychosis, cardiovascular complications, and premature deaths from unintentional overdose. In Pakistan, prescription drugs, which are misused or abused by some patients, are often obtained from pharmacies. However, intervention for prescription drugs misuse has not been tested in this setting. Objectives: The objective of the study was to assess knowledge, perception and attitudes regarding interventions towards the abuse of prescription medicines (PM) among practicing pharmacists in Pakistan. Materials and Methods: This transversal study was conducted from June to September 2015 by adopting a pre validated questionnaire distributed to practicing pharmacists in different private and public sector hospitals of Karachi. Descriptive statistics were used to demonstrate participants' demographic information and their response to the questionnaire items. Pearson's chi-squared test was executed to evaluate the association of gender, age, organization, and experience of pharmacists with their response. A $p$ value $<0.05$ was considered as significant. Results: The study revealed that mass population $75 \%$ claimed that they had adequate knowledge of prescription medicine abuse. $81.25 \%$ perceived drug abuse as a problem and $88.10 \%$ considered that the role of pharmacist was very important in prevention of PM abuse. However pharmacists were not confident that patients would take their advice, respond positively and make needed behavior changes. Respondents also were not confident regarding the manner in which screenings and interventions should occur. Conclusion: Findings from this study will assist health authorities to formulate appropriate health promotion interventions to control and prevent abuse of prescription medicines. Actions directed at early intervention, capacity building, education, public health initiatives and law enforcements will hopefully curb the menace of PM abuse.

\footnotetext{
${ }^{*}$ Corresponding author.
}

How to cite this paper: Shakeel, S., Iffat, W., Ibrahim, S. and Imam, S. (2015) Pharmacists' Knowledge, Attitudes and Beliefs Regarding Intervention for Prescription Medicines Abuse. Open Access Library Journal, 2: e2036. 


\title{
Keywords
}

Prescription Medicine Abuse, Knowledge, Attitude, Pharmacist, Pakistan

\author{
Subject Areas: Public Health
}

\section{Introduction}

Pharmaceutical products have been abused all through the ages, and the recent epidemic of prescription drug abuse represents the newest wave of a long-standing problem. Irrational use of drugs by different age groups is a rising public health problem globally [1] [2]. Inappropriate use of drugs can be classified into either "abuse"; typically defined as use of a medication for nonmedical purpose (i.e., experience a mind altering effect), or "misuse"; which is the use of medications for a legitimate medical reason, yet in ways other than as directed, in most cases by alteration of either dose or duration of use [3]. While the terms "abuse" and "misuse" are used interchangeably when talking about illicit drugs, differentiation between them becomes more important when talking about prescription or over-the counter (OTC) medications. Prescription drug abuse is a complex public health dilemma with factors that complicate resolution. Prescription drug abuse emphasizes the problems of overprescribing and drug diversion, at the expense of attending to equally important problems of under prescribing. Independent research has documented significant knowledge gaps in those health care professionals responsible for prescribing, dispensing, or administering opioid analgesic. The risks interrelated with the misuse of products can influence the abuser himself i.e., overdose, masking the diagnosis of a serious disease due to the prolonged use of product, interference with a normal physiological function, and physical or psychological dependence due to the excessive use of these products. Society has to pay the cost of such problem, as the effect would be reflected on the society in the form of drug wastage and cost of management of abusers [2].

Prescription drugs of abuse come under the same pharmacological classes as their non-prescription counterparts. The potential factors associated with abuse versus safe therapeutic use of these agents related to the expected variables include: dose, route of administration, co-administration with other drugs, context of use, and expectations. Research has shown that opioid analgesics, stimulants, psychotherapeutic drugs, antihistamines, stimulant laxatives and sympathomimetics were among the most widely misused and abused prescribed and OTC medications [4] [5].

The qualification of healthcare professionals is essential to enable them to act in the spheres of prevention and treatment. With regard to pharmacists, they have a professional responsibility to ensure that patients receive adequate therapy and are professionally mandated to provide patient counseling on the correct use of medications. Therefore, there is always a need for pharmacists to have the confidence and ability to offer psychosocial and medication recommendations to patients and other health care professionals about addiction related issues and their associated hazards, particularly because of the difficulties involved in recognizing addiction [6]. Few studies have investigated the misuse of drugs because most concentrated on the appropriateness of medication usage rather than the pattern of misuse/abuse of drugs [2]. Therefore, the objective of the study was to assess knowledge, perception and attitudes regarding interventions towards the abuse of prescription medicines (PM) among practicing pharmacists in Pakistan.

\section{Materials and Methods}

\subsection{Study Design and Setting}

This transversal study was conducted from June to September 2015 by adopting a pre validated questionnaire distributed to practicing pharmacists in different private and public sector hospitals of Karachi. Overall, seventy six pharmacists participated in the study. They were encouraged to fill up the given questionnaire on spot. After completion the questionnaires were subsequently collected for further analysis.

\subsection{Ethical Approval}

Prior verbal ethical approval was taken from each institution's head of department to instigate the study in their 
institute. Each institution's head of department and the pharmacists' participating in the study were briefed about the rationale of the study. Participants were assured about the confidentiality of their personal information and responses.

\subsection{Data Collection}

The basic tool selected to conduct the study was questionnaire which was developed through the review of literature and researches available in this area. The questionnaire was prepared to acquire the demographics of the pharmacists, information about their attitude and knowledge towards drug abuse and interventions.

\subsection{Statistical Analysis}

The filled questionnaires were analyzed by using SPSS 20.0. Descriptive statistics were used to demonstrate pharmacists' demographic information and their response to the questionnaire items. Pearson's chi-squared test was executed to evaluate the association of gender, age, organization, and experience of pharmacists with their response. A $p$ value $<0.05$ was considered as significant.

\section{Results and Discussion}

Out of 100 survey questionnaires, only 76 were returned back in useable form. Hence the response rate was $76 \%$. Table 1 showed the demographic of the study population. The study population comprised of $34.09 \%$ males and $65.91 \%$ females. More than half (52.08\%) were having an experience of 1 - 5 years. More than $75 \%$ were pharmacy graduates.

Mass population $75 \%$ claimed that they have adequate knowledge of prescription medicine abuse. $81.25 \%$ perceived drug abuse as a problem whereas $8.33 \%$ did not perceive drug abuse as a problem. $88.10 \%$ considered that the role of pharmacist is very important in prevention of PM abuse. Figure 1 illustrates the evidence of

Table 1. Characteristics of study population.

\begin{tabular}{|c|c|}
\hline Characteristics of study population & Percentages (\%) \\
\hline \multicolumn{2}{|l|}{ Gender } \\
\hline Male & $34.09 \%$ \\
\hline Female & $65.91 \%$ \\
\hline \multicolumn{2}{|l|}{ Age (years) } \\
\hline $25-30$ & $77.78 \%$ \\
\hline $31-35$ & $13.33 \%$ \\
\hline $36-40$ & $6.67 \%$ \\
\hline $41-50$ & $2.22 \%$ \\
\hline \multicolumn{2}{|l|}{ Year of experience } \\
\hline Less than 1 year & $22.92 \%$ \\
\hline $1-5$ years & $52.08 \%$ \\
\hline 5 - 10 years & $10.42 \%$ \\
\hline $10-15$ years & $4.17 \%$ \\
\hline More than 15 years & $10.42 \%$ \\
\hline \multicolumn{2}{|l|}{ Level of education } \\
\hline Pharm D/B.Pharm & $76.09 \%$ \\
\hline M.Pharm & $4.35 \%$ \\
\hline M.Phil & $19.57 \%$ \\
\hline
\end{tabular}




\section{Evidence of abuse of PM noticed by pharmacists}

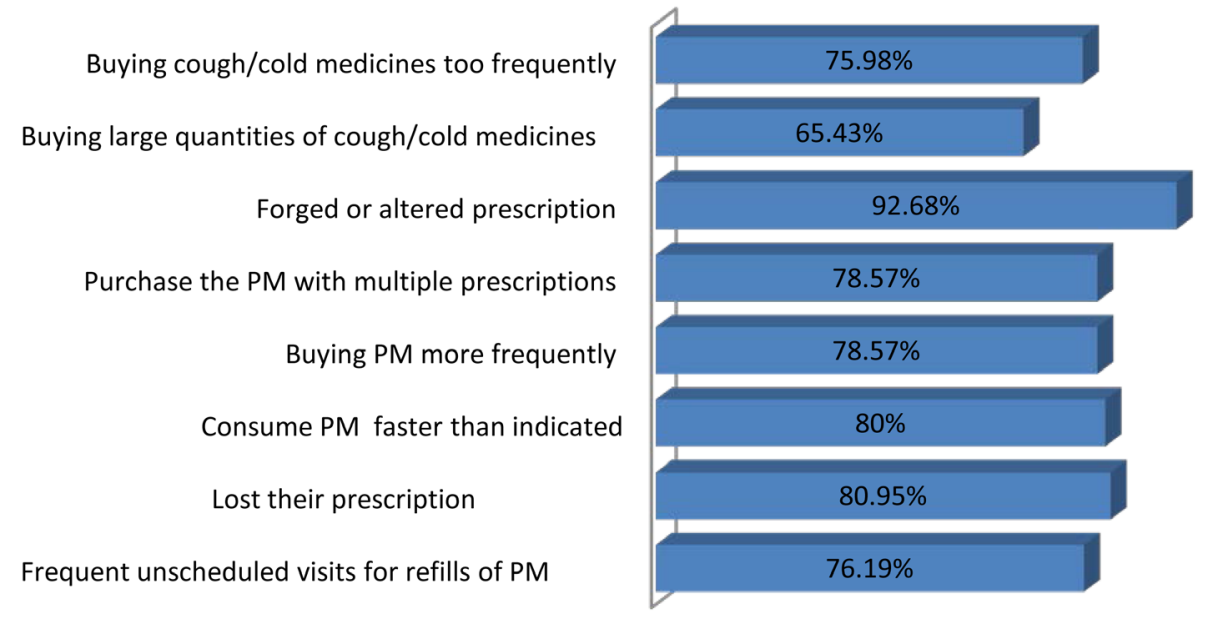

Figure 1. Evidence of abuse of PM noticed by pharmacists.

abuse of PM noticed by pharmacists. Some customers presented forged or altered prescription forms was the most commonly observed practice (92.68\%) of patients to buy PM. Some patients regularly claim to have lost their prescription forms and request for replacement (80.95\%) and some patients consume prescription medicines much faster than indicated (80\%).

On inquiring about the non-medical purposes for which people need prescription medicine, $48.84 \%$ patients uses PM to relax or relieve tension (Figure 2). Others non-medical purposes includes to induce sleep (20.93\%), to maintain an addiction and prevent withdrawal (13.95\%) and to experiment with the mental effects of substance $(9.30 \%)$. Another study depicted that laxatives, were often abused in the mistaken belief that their use will prevent calorie absorption and weight gain. However, their excessive use may also be observed in patients who believe that daily bowel evacuation is necessary for good health [7]. Abuse of stimulant laxatives may lead to a number of complications including diarrhea with associated sodium and water loss, which in turn stimulates the renin angiotensin system, leading to potassium loss and hypokalaemia [8]. Many non-prescription analgesic products contain codeine in combination with aspirin or paracetamol. Abuse of such products can result in non-opioid toxicity. It is also recommended that extended use of combination analgesic products, even for genuine complaints, may contribute to analgesic nephropathy [9].

Substance abuse and addiction are growing public health problems. While science has moved forward and clinical methods have improved, the drug abuse problem has grown more complex. Pharmacists are potentially in a position to be of great assistance in ameliorating these threats yet might not be receiving the education and training to do so effectively [10]. Pharmacists may find themselves ill prepared to respond effectively when approached by patients. Since substance abuse has been a somewhat arcane specialty area, health professionals for the most part have not been expected to possess a working knowledge of this issue [11]. Pharmacists receive scant information on drug abuse during their undergraduate courses. The professional role of pharmacists requires them to provide up-to-date information to both patients and providers and concurrently monitor use and abuse of controlled substances as mandated by the Drug regulatory authorities. Currently, pharmacists receive a minimum of five years of rigorous scientific and clinical education but often receive little or no education on the topics of drug abuse and drug addiction [12]. The current study revealed a strong inclination of pharmacists to receive more training about the identification and management of the problem of drug misuse and abuse. Around $44 \%$ considered that they possess too little training in helping patients who misuse PM. Half of the population believed that they have too few self-help or written material available for helping patients and they knew too little about how to identify patients who misuse PM when they do not have obvious symptoms of excess use. Other study also revealed that pharmacists respondents overwhelmingly felt that educational preparation in this area is important [10]. Glenda F. reported that a problem of drug abuse exists; yet it is difficult to identify and to resolve within the current practice guidelines, unless new and innovative strategies are developed and implemented [7]. On asking about the patients' reaction of pharmacist intervention more than half (58.97\%) of the pharmacists believed that patients would resent being asked about their possible misuse of PM (Figure 3). 


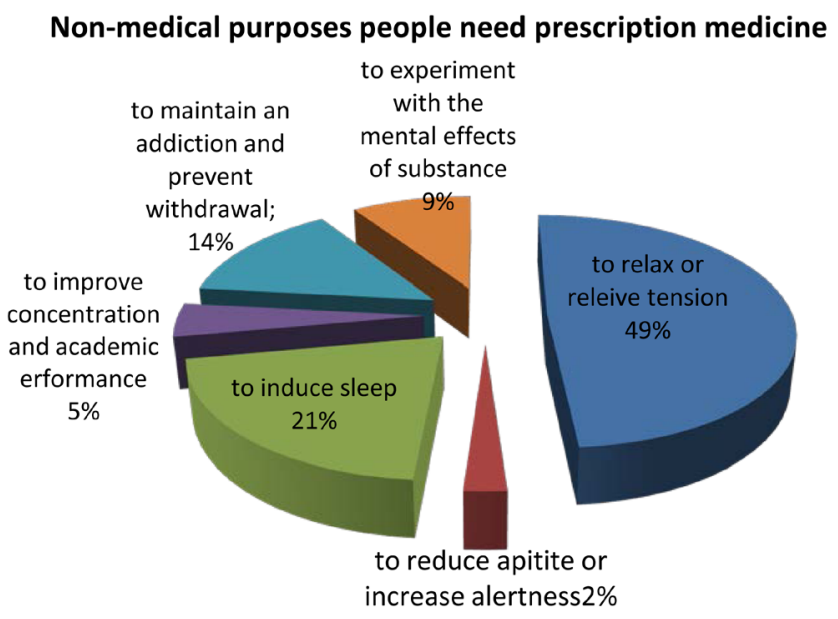

Figure 2. Non-medical purposes people need prescription medicine.

Patient reactions to the intervention of Pharmacist in PM abuse

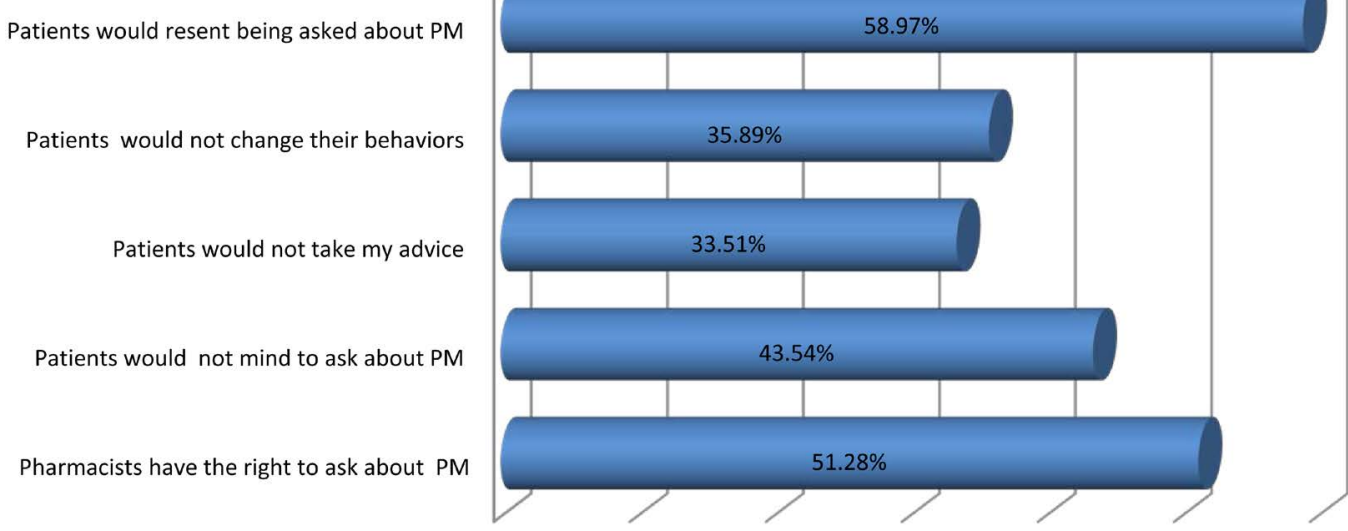

Figure 3. Patient reactions to the intervention of pharmacist.

Around 52\% opined their patients believe that pharmacist have the right to ask them about their use of PM. 43.54\% considered that patients in their pharmacy would probably not mind being contacted about their use of PM, if their use was assessed to be risky or harmful. Current practice guidelines for dealing with such patients recommend that pharmacists should use their professional opinion in order to prevent the supply of products apt to abuse/misuse, and if needed the sale of such products should be refused. General policies such as keeping the product out of sight and telling the suspected abuser that it was not available, or refusing the sale, will help prevent excessive supply. Though, such policies may encourage individuals to go to another pharmacy in the area, where they may be able to obtain the product [7]. Pearson's chi-squared test was executed to evaluate the association of gender, age, organization, and experience of pharmacists with their response. Significant association was observed between the experience of pharmacists and their responses to the questionnaire items. However no significant association was found between age, gender and organization on the responses.

The present findings suggest that additional training on all subjects surrounding the science of addiction, counseling, and standards of care for the rational and optimum treatment is warranted. Additional research is recommended to determine the educational needs of practicing pharmacists to better prepare them to assume a leadership role in detecting and preventing prescription drug abuse.

\section{Conclusion}

This survey provides an initial insight into pharmacists' interest, belief and opinions about prescription medicine 
abuse. Pharmacists were not confident that patients would take their advice, respond positively and make needed behavior changes. Respondents also were not confident regarding the manner in which screenings and interventions should occur. There is a need to implement a well-structured training on the identification, prevention and management of prescription and OTC drug misuse and abuse. A continuing pharmacy education program for practicing pharmacists is needed which will set a concrete foundation for healthcare professionals to be meticulously involved in drug misuse and abuse activities in their future practices.

\section{Acknowledgements}

The authors wish to acknowledge Mehak Aziz, Sidra Khalid and Yousra Jawed for their contribution in compiling data.

\section{Conflicts of Interest}

All authors have none to declare.

\section{References}

[1] Pates, R., McBride, A.J., Li, S. and Ramadan, R. (2002) Misuse of Over-the-Counter Medicines: A Survey of Community Pharmacies in a South Wales Heath Authority. Pharmaceutical Journal, 268, 179-182.

[2] Albsoul-Younes, A., Wazaify, M., Yousef, A.-M. and Tahaineh, L. (2010) Abuse and Misuse of Prescription and Nonprescription Drugs Sold in Community Pharmacies in Jordan. Substance Use \& Misuse, 45, 1319-1329. http://dx.doi.org/10.3109/10826080802490683

[3] Wazaify, M., Hughes, C.M. and McElnay, J.C. (2006) The Implementation of a Harm Minimisation Model for the Identification and Treatment of Over-the-Counter Drug Misuse and Abuse in Community Pharmacies in Northern Ireland. Patient Education and Counseling, 64, 136-141. http://dx.doi.org/10.1016/j.pec.2005.12.008

[4] McCabe, S.E., Knight, J.R., Teter, C.J. and Wechsler, H. (2005) Non-Medical Use of Prescription Stimulants among US College Students: Prevalence and Correlates from a National Survey. Addiction, 100, 96-106. http://dx.doi.org/10.1111/j.1360-0443.2005.00944.x

[5] Compton, W.M. and Volkow, N.D. (2006) Abuse of Prescription Drugs and the Risk of Addiction. Drug and Alcohol Dependence, 83, S4-S7. http://dx.doi.org/10.1016/j.drugalcdep.2005.10.020

[6] Auersperger, I., Topič, M.D., Maver, P., Pušnik, V.K., Osredkar, J. and Lainščak, M. (2012) Doping Awareness, Views, and Experience: A Comparison between General Practitioners and Pharmacists. Wiener Klinische Wochenschrift, 124, 32-38. http://dx.doi.org/10.1007/s00508-011-0077-x

[7] Hughes, G.F., McElnay, J.C., Hughes, C.M. and McKenna, P. (1999) Abuse/Misuse of Non-Prescription Drugs. Pharmacy World and Science, 21, 251-255. http://dx.doi.org/10.1023/A:1008788726842

[8] Müller-Lissner, S. (1993) Adverse Effects of Laxatives: Fact and Fiction. Pharmacology, 47, 138-145. http://dx.doi.org/10.1159/000139853

[9] Eknoyan, G. (1994) Current Status of Chronic Analgesic and Nonsteroidal Anti-Inflammatory Drug Nephropathy. Current Opinion in Nephrology and Hypertension, 3, 182-188. http://dx.doi.org/10.1097/00041552-199403000-00008

[10] Wenthur, C.J., Cross, B.S., Vernon, V.P., Shelly, J.L., Harth, B.N., Lienhoop, A.D., et al. (2013) Opinions and Experiences of Indiana Pharmacists and Student Pharmacists: The Need for Addiction and Substance Abuse Education in the United States. Research in Social and Administrative Pharmacy, 9, 90-100. http://dx.doi.org/10.1016/j.sapharm.2012.03.003

[11] Tommasello, A.C. (2004) Substance Abuse and Pharmacy Practice: What the Community Pharmacist Needs to Know about Drug Abuse and Dependence. Harm Reduction Journal, 1, 3. http://dx.doi.org/10.1186/1477-7517-1-3

[12] Lafferty, L., Hunter, T.S. and Marsh, W.A. (2006) Knowledge, Attitudes and Practices of Pharmacists Concerning Prescription Drug Abuse. Journal of Psychoactive Drugs, 38, 229-232. http://dx.doi.org/10.1080/02791072.2006.10399848 